\title{
Family Influences during Childhood on African American Women's Sexual Behavior during Young Adulthood
}

\author{
Keisha Carr Paxton", ${ }^{1, *}$ Naomi M. Hall ${ }^{2}$, Edtna Bogarin ${ }^{1}$ \\ ${ }^{1}$ California State University, Dominguez Hills, Department of Psychology, 1000 E. Victoria Street, Carson, CA 90747 , \\ United States of America (USA) \\ ${ }^{2}$ Winston-Salem State University, Department of Psychological Sciences, Winston-Salem, NC 27110 \\ * Corresponding Author: kpaxton@csudh.edu
}

Copyright $@ 2014$ Horizon Research Publishing All rights reserved.

\begin{abstract}
The present study examined family influences during childhood on young adult sexual risk behavior. Prior research suggests that parental responsiveness and communication with adolescents about sexuality delays sexual activity and prevents risky behavior. One hundred twenty four African American women ages 18 to 25, inclusive, completed a survey assessing sexual behavior, childhood health influences, and other sociodemographic information. The results reveal that mothers are a primary influence on sexual behavior in adulthood, as measured by acquisition of a sexually transmitted infection. The results of this study underscore the importance of mother-daughter communication about sex during childhood and adolescence and have implications for sexual health interventions.
\end{abstract}

Keywords African American Women, Sexual Behavior, Parent-Child Communication, Sexually Transmitted Infections

\section{Introduction}

Important research has been done on teen sexuality that brings forward factors that may influence future sex education and disease prevention. The future and well-being of adolescents cannot be predicted, but it can be influenced. This review will include literature that supports different reasons for risky adolescent behavior. Major influencing factors include parental monitoring, communication with parents, family structure, and family influences on African American adolescents. Researching risky behavior among teens brings to attention variables that predict sexually transmitted infections (STIs). Research in this area finds support for the role of parents as a predictor of youth sexuality and risky behavior [1-7]. Specifically, prior research supports that communication with parents [3,6-9], mother's responsiveness [10], and closeness [1] between parent and adolescent can have an effect on sexual behavior.

Parental monitoring is an important part of preventing risky teen behavior. When there are fewer children in a household, there tends to be more parental monitoring among them [6]. Compared to males, females who perceive more monitoring from their mothers, are less likely to be involved with deviant peers, and are more likely to report less delinquency, where maternal involvement does not differ between genders [11]. Parental monitoring is positively related to the amount of communication there is between a parent and their child [3], positively related to condom use, and negatively related to drug use [4]. In general, greater parental monitoring among boys and girls was associated with less and later sexual experience and safer sex.

Communication with parents about sex is an important measure of examined in the literature and in exploring parent-child communication, gender differences emerge. Fasula \& Miller [10] found that, among an African American and Hispanic sample, those participants who delayed sexual activity rated their mothers high in responsiveness. Wight et al. [6] found that boys are more likely to talk to fathers and girls more likely to talk to mothers about sexual matters. Among Latino and Anglo adolescents, females are more likely to communicate with their mothers more than males and that sibling communication was more common than parent communication [9]. Nevertheless, if children live with parents they are more likely to talk to either of them and less likely to talk to parents not living with them [6]. Adolescents who communicate less with their parents are less likely to use any type of contraception [2,3,12]. Furthermore, these adolescents are less likely to communicate with their partners on sexual issues, which diminishes their self-efficacy in order to be able to initiate condom use or say "no" to sex [3]. Furthermore, there was a positive association exists between parent-adolescent communication on sexuality and adolescent communication with their partner regarding initiating condom use $[3,12,13]$. Hovell et al. [4] found that sexual behavior is associated to the amount of communication with parent and comfort level.

Parent-child communication appears to be a good way to prevent sexual activity in most studies on this topic, but there 
are some studies that suggest such discussions may be associated with negative outcomes. Davis \& Friel [8] found that children with mothers who talked about sex to their boys and girls were more likely to have earlier sexual debut than those that are not talked to about sex. According to Aronwitz and colleagues [1], mother daughter closeness determined that there would be more discussion about boys and sex. The role of father communication about sex appears less salient than that of mothers. There is lower trust and communication perceived by biological fathers and fathers not living in the home [14]. Nevertheless, contact level is found to make a difference in father-daughter attachment quality and in girls' psychosocial function [14].

Family influences have a great impact on the overall functioning, risky behaviors and sexuality among African American adolescents. As discussed, having a high quality relationship with mothers is associated with delay of sexual debut among girls [8]. Additionally, Bynum and Kotchick [15] found an association between mother-adolescent relationship quality and high self-esteem. Given the above review, the purpose of this study was to explore correlates of risky sexual behavior among young African American girls, and how their behavior increases their risk for HIV and STIs. There were two research questions guiding this study. The first question was from whom do young African American women report learning about sex? The second question was what impact does sexual communication from significant individuals (e.g., parents, friends, adult females) during childhood and/or adolescent have on later sexual behavior as measured by acquisition of a sexually transmitted infection in young adulthood?

\section{Method}

\subsection{Participants}

This study was part of a larger mixed methods study examining sexuality among African American young adult women. One hundred and thirty-two participants were recruited from three community college campuses in Southern California. These institutions were selected because each campus had a high percentage of African American students. Community college students were selected due to the dearth of research on this very diverse population. Furthermore, this population of African American women is likely to represent the general public of African American women more so than populations used in other research (e.g., impoverished samples and university students). Participants ranged in age from 18-25 with a mean of 20.9 (S.D. $=2.24)$. About half of the sample (51.1\%) was employed full-time or part-time. Nearly one-third $(29.5 \%)$ had at least one child. Almost all (92.4\%) of the sample identified as heterosexual.

\subsection{Recruitment}

A convenience sampling method was used to recruit participants. Recruitment methods included classroom presentations about the study, fliers handed out on campus, tables set up at campus events, and word of mouth. To be included in the study, participants had to be between ages 18 and 25 inclusive, a student at one of the three community colleges, female, and self-identify at African American.

\subsection{Measures}

Demographic information was collected from participants, including information regarding age, education, employment, and relationship status. Participants also completed author-developed questions regarding their current sexual behaviors and history of sexually transmitted diseases. Examples of these questions include age at first intercourse, frequency of condom use, experience with anal and oral sex, sex while under the influence of drugs and/or alcohol, history of pregnancies, and HIV and STI testing history and results. Information regarding who was in the home with them while they were growing up and who provided them with information about sex during their formative years was also obtained. Participants were asked, "Who were the individuals that talked to you about sex [while growing up]?" They were then provided with an extensive list from which to select as many family members (close and extended), friends, and others who may have provided information about sex.

\subsection{Procedures}

After explaining the study to students meeting the inclusion criteria, participants were given an informed consent form to read. Research staff then reviewed the consent form with participants and answered any questions they may have had. Participants were then given the survey and provided with a secluded area, free from distraction to complete the paper-pencil survey. The survey took approximately 20 minutes to complete. Participants each received two movie passes for participating in the survey.

The institutional review board of Charles R. Drew University of Medicine and Science approved the conduct of this study. Furthermore, a Certificate of Confidentiality was provided by the National Institutes of Health for this study.

\section{Results}

Although 132 women completed the survey, 124 participants are used in these analyses as eight individuals did not complete the survey. One-fifth $(21 \%)$ of the sample reported a history of having been diagnosed with a sexually transmitted infection (STI). To ascertain from whom young African American report learning about sex, descriptive analyses were conducted. The majority of participants reported receiving messages regarding sex from more than one individual. Two-thirds $(65 \%)$ reported their mothers to be a source of information about sex. Second to mothers 
were female friends, who comprised $27.9 \%$, followed by aunts $(22.5 \%)$. A significant portion (16.3\%) of participants also reported that their fathers talked to them about sex. Table 1 presents all of the sources of information about sex during childhood and adolescence that participants reported.

Table 1. Sources Participants Reported Provided Information about Sex during Childhood/Adolescence

\begin{tabular}{|c|c|}
\hline Informant & $\begin{array}{c}\text { \% reporting this person as } \\
\text { a source }\end{array}$ \\
\hline Mother & 65 \\
\hline Female friends & 27.9 \\
\hline Aunt & 22.5 \\
\hline Father & 16.3 \\
\hline Grandmother & 10.9 \\
\hline Boyfriend & 9.3 \\
\hline Another adult & 9.1 \\
\hline Sister & 5.4 \\
\hline
\end{tabular}

Table 2. Chi Square Analysis of Relationship between Mother Talking to participants about Sex and Participants Reporting a Sexually Transmitted Infection

\begin{tabular}{|c|c|c|c|c|}
\hline & & \multicolumn{3}{|c|}{ Ever had an STI } \\
\hline & & Yes & No & Total \\
\hline \multirow{3}{*}{ Mother talked to them about sex } & Yes & 12 & 67 & 79 \\
\hline & No & 14 & 31 & 45 \\
\hline & Total & 26 & 98 & 124 \\
\hline & \multicolumn{4}{|c|}{$\chi^{2}=(1,124)+4.39, p<.05$} \\
\hline
\end{tabular}

Chi square analyses were used to examine the relationships between sexual communication during childhood and/or adolescence and the acquisition of a sexually transmitted infection in young adulthood. A series of chi square analyses were conducted for each of the primary individuals from whom they reported learning about sex. These individuals included, in order of frequency reported, mother, female friends, aunt, father, and grandmother. A significant relationship between the mother speaking to them about sex during childhood and/or adolescence and later development of a sexually transmitted infection was found $\left(\chi^{2}=(1,124)=4.39, \mathrm{p}<0.05\right)$. These results show that participants whose mothers talked to them about sex were less likely to report having had an STI. These results are presented in Table 2. Significant relationships between acquisition of an STI and other sexual informants were not found.

\section{Discussion}

The purpose of this study was to determine where young African American women receive messages about sexuality in childhood and/or adolescence and the impact of these messages on later sexual behavior as measured by presence or absence of a STI. Mothers served as the most common source of sexual information during participants' youth. Receiving information about sex from mothers was also associated with not acquiring an STI. Other sources of sexual information (e.g., female friends, aunts, and fathers) during childhood were not associated with later development of an STI.

Research about the influence of parents on sexual behavior is somewhat mixed. Little and Rankin [16] found that parental characteristics did not show a significant relationship with sexual activity of adolescents. However, the results of this study are consistent with other research that suggests that mothers are the strongest influences on sexual behavior among African American young women. Our findings are consistent with other studies that find mothers to be significant influences on sexual behaviors of girls [9]. Furthermore, communication between mothers and daughters may serve as a protective factor in reducing sexual risk behaviors among African American girls $[3,12,13]$. The findings of the current study are significant as they support the idea of mother-daughter communication being a protective factor in STI prevention among African American young women.

\section{Conclusions}

This research has important implications for the development of sexual health interventions for African American young women. Rather than providing typical sexual health interventions that espouse merely focusing on providing sexual health information to groups of African American females, these findings provide information for alternative approaches to health promotion. Including mothers in the intervention efforts may prove beneficial to a young African American woman's sexual behavior. A parallel intervention with mothers that would arm them with appropriate and up-to-date sexual health information would provide multiple means for young African American females to learn about sexual health behaviors. Furthermore, such an intervention can promote healthy and open communication between mother and daughter, thus modeling healthy sexual communication in future romantic relationships.

\section{Acknowledgements}

This study was supported by the National Institute of General Medical Sciences (\# S06- GM068510-01). We gratefully acknowledge the support of administrators at the community colleges who graciously allowed us to conduct this study on their campuses. 


\section{REFERENCES}

[1] T. Aronowitz, R. E. Rennells, E. Todd. Heterosocial behaviors in early adolescent African American girls: The role of mother-daughter relationships, Journal of Family Nursing, Vol. 11, No.2, 122-139, 2005.

[2] D. P. Deptula, D. B. Henry, M. E. Schoeny. How can parents make a difference? Longitudinal associations with adolescent sexual behavior. Journal of Family Psychology, Vol. 24, No.6, 731-739, 2010.

[3] R. J. DiClemente, G. M. Wingood, R. Crosby, B. K. Cobb, K. Harrington, K., S. L. Davies. Parent-adolescent communication and sexual risk behaviors among African American adolescent females, The Journal of Pediatrics, Vol. 139, No. 3, 407-412, 2001.

[4] B. Stanton, X. Li, R. Pack, L. Cottrell, C. Harris, J. M. Burns. Longitudinal influence of perception of peer and parental factors on African American adolescent risk involvement, Journal of Urban Health: Bulletin of the New York Academy of Medicine, Vol. 79, No. 4, 536-548, 2002.

[5] T. P. Thornberry, C. A. Smith, G. J. Howard. Risk factors for teenage fatherhood, Journal of Marriage and the Family, Vol. 59, No. 3, 505-522, 1997.

[6] D. Wight, L. Wiliamson, M. Henderson. Parental influences on young people's sexual behavior: A longitudinal analysis, The Association for Professionals in Services for Adolescents, Vol. 29, No. 4, 1-22, 2005.

[7] D. Wight, D. Fullerton. A review of interventions with parents to promote the sexual health of their children, Journal of Adolescent Health, Vol 52, No. 1, 4-27, 2013.

[8] E. C. Davis, L. V. Friel. Adolescent sexuality: Disentangling the effects of family structure and family context, Journal of Marriage and Family, Vol. 63, No. 3, 669-681, 2001.
[9] M. Hovell, C. Sipan, E. Blumberg, C. Atkins, R. C. Hofstetter, S. Kreitner. Family influences on Latino and Anglo adolecents' sexual behavior, Journal of Marriage and the Family, Vol. 56, No. 4, 973-986, 1994.

[10] A. M. Fasula, K. S. Miller. African-American and Hispanic adolescents' intentions to delay first intercourse, Vol.38, No. 3, 193-200, 2006.

[11] M.A. Bowman, H. M. Prelow, S. R. Weaver. Parenting behaviors, associated with deviant peers, and delinquency in African American adolescents: A mediated-moderation model, Journal of Youth Adolescence, Vol. 36, No. 4, 517-527, 2007.

[12] M. S. Hicks, A. McRee, M. Eisenberg. Teens talking with their partners about sex: The role of parent communication, American Journal of Sexuality Education, Vol 8, No.1-2, 1-17, 2013.

[13] E. S. Pingel, J. A. Bauermeister, K. S. Elkington, S. Fergus, C. H. Caldwell, M. A. Zimmerman. Condom use trajectories in adolescence and the transition to adulthood: The role of mother and father support, Journal of Research on Adolescence, Vol 22, No. 2, 350-366, 2012.

[14] R. L. Coley. Daughter-father relationship and adolescent psychosocial functioning in low-income African American families, Journal of Marriage and Family, Vol. 65, No. 4, $867-875,2003$

[15] M. S. Bynum, B. A. Kotchick. Mother-adolescent relationship quality and autonomy as predictors of psychosocial adjustment among African American adolescents. Journal of Child and Family Studies, Vol. 15, No. 5, 529-542, 2006.

[16] C. B. Little, A. Rankin. "Why do they start it? Explaining reported early-teen sexual activity," Sociological Forum, Vol. 16. No. 4., 703-729, 2001. 